\title{
Oswald Spengler und die ,Formensprache der Geschichte
}

\begin{abstract}
This essay illustrates how Spengler, in his work The Decline of the Occident, aims to understand the Weltanschauungen and the sense of life of a particular epoque by systematically investigating its artistic 'world of forms'. According to Spengler, historians and philosophers who intend to deal with universal history have the task of transforming themselves into 'visionaries' and at the same time familiarising themselves in depth with the methods of investigation used in art history. The contribution shows how Spengler carefully investigated the results of an history of art that is more and more connected to the history of ideas (thanks to Alois Riegl, Josef Strzygowski and Wilhelm Worringer), and how he drew important suggestions from Marie Luise Gothein's Monographie zur Geschichte der Gartenkunst (1914).
\end{abstract}

1

Die Vorstellungen und Sichtweisen, die das „Lebensgefühl“ einer Epoche prägen, kristallisieren sich - nach Oswald Spengler - in der Vielfältigkeit ihrer „künstlerischen Formenwelt“" heraus (Spengler 1972, 300).

In seinem Hauptwerk von 1922 stellt Spengler fest, dass er seine Untersuchung nicht hätte durchführen können, wenn er Nietzsche nicht sorgfältig studiert hätte: „Wir waren bisher blind - er schreibt - für den unermeßlichen Reichtum [...] der moralischen Formensprache“. Tatsächlich ist es erst nach Nietzsche möglich, zu begreifen, dass „eine Moral eine in sich geschlossene Formenwelt [ist], die ein Lebensgefühl zum Ausdruck bringt“ (Spengler 1972, 441).

Laut Spengler, der sich dabei weiterhin auf Nietzsche stützt, müsse sich der historische Sinn als fähig erweisen, die Schranken und Grenzlinien zu durchbrechen, die die Geisteswissenschaften traditionell trennen. Wer die Kulturgeschichte in der Vielfalt ihrer Aspekte untersuchen will, wird eine neue ,historische Morphologie“ entwickeln müssen, die darauf abzielt, die „Ursymbole“ und die verworrene „Formensprache der Geschichte“ (Spengler 1972, 233 u. 601) zu deuten. Eine „theoretisch durchleuchtete Kunst der historischen Betrachtung“ wird also die Aufgabe haben, die „sichtbare Geschichte“ in ihrer Fülle von „Zeichen“ und „formgewordenen“ Werte und Ideale zu entschlüsseln. Um in dieser Richtung voranzukommen, muss man zunächst anerkennen, dass „die Morphologie 
der Geschichte bis zum heutigen Tag - so Spengler - eine kaum entdeckte Welt von Problemen geblieben“ ist (Spengler 1972, 512).

Das „Studium der morphologischen Verwandtschaft, welche die Formensprache aller Kulturgebiete innerlich verbindet“ (Spengler 1972, 8), zwingt Historiker und Philosophen in gewisser Weise $\mathrm{zu}$,Visionären` $\mathrm{zu}$ werden, denen es nicht schwer fällt, intuitiv das Lebensgefühl und die Verhaltensnormen zu erblicken, die sich in einer bestimmten künstlerischen ,Form herauskristallisiert haben:

Die Formenwelt der Künste für eine Durchdringung des Seelischen ganzer Kulturen nutzbar zu machen, indem man sie durchaus physiognomisch und symbolisch auffaßt, ist ein Unternehmen, dessen bisher gewagte Versuche von unverkennbarer Dürftigkeit sind. Man weiß kaum etwas von einer Psychologie der metaphysischen Grundformen aller großen Architekturen [...]. Die Geschichte der Säule ist noch nicht geschriebene worden. Man hat keinen Begriff von der Tiefe einer Symbolik der Kunstmittel, der Kunstwerkzeuge (Spengler 1972, 277).

Um sich auf dem Gebiet der Geschichtsphilosophie zu orientieren, ist es unerlässlich, sich mit der Kunst vertraut zu machen, die in einer bestimmten Gestalt, in einem bestimmten Bild enthaltenen Ideen und Vorstellungen zu erschließen und zu interpretieren. Man kann das „höhere Denken“ einer bestimmten Kultur verstehen, wenn man z. B. „das Schicksal der Säule“ verfolgt, „vom ägyptischen Grabtempel an, wo sie in Reihen den Wanderer gleitet, über den dorischen Peripteros, dessen Körper sie zusammenhält, und die früharabische Basilika, deren Innenraum sie stützt, bis zu den Fassaden der Renaissance, an welchen sie den aufstrebenden Zug zum Ausdruck bringt“ (Spengler 1972, 214).

In diesem Sinne muss sich der Philosoph, der die entscheidenden Züge einer bestimmten Epoche entschlüsseln will, mit einer schier unendlichen Kette von Formen, Figuren und Images befassen:

Unzählige Gestalten, in endloser Fülle auftauchend, verschwindend, sich abhebend, wieder verfließend, ein in tausend Farben und Lichtern blinkendes Gewirr von anscheinend freiester Zufälligkeit - das ist zunächst das Bild der Weltgeschichte, wie sie als Ganzes vor dem innern Auge sich ausbreitet (Spengler 1972, 139)

Mit seinen geschichtsphilosophischen Erörterungen will Spengler erläutern, wie sich jedes Zeitalter durch eine besondere Art auszeichnet, Raum und Zeit zu erfassen. Seine Betrachtungen, die sich eng an die Untersuchungen von Kunsthistorikern wie Alois Riegl, Josef Strzygowsky und Wilhelm Worringer anlehnen, machen deutlich, dass die Veränderungen der „Formensprache“ im künstlerischen Bereich - sichtbar in Architektur und Ornamentik, Malerei und Skulptur - 
die Folge von geschichtlichen Umwandlungen sind, die nicht nur die Kunstgeschichte betreffen:

Es ist für das Bild des Menschlichen, das metaphysische wie das ethische und künstlerische, schlechthin entscheidend, ob der Einzelne sich als Körper unter Körpern oder als Mitte eines unendlichen Raumes fühlt [...]. Die apollinische Seele, euklidisch, punktförmig, empfand den empirischen, sichtbaren Leib als den vollkommenen Ausdruck ihrer Art, zu sein (Spengler 1972, 331).

Spengler geht es darum zu zeigen, dass die Antike nicht das ideale Terrain ist, wie die Klassizisten glauben, das im Laufe der Geschichte immer wieder Wiedergeburten und geistige Erneuerungen ermöglicht. Seiner Ansicht nach zeigt sich die Beschränktheit der Horizonte des griechisch-römischen Weltbildes in erster Linie darin, dass das „antike Kunstwollen“ ausschließlich als „Kultus des Körperhaft-Plastischen“ gilt (Spengler 1972, 301 u. 313). In Griechenland sind Tempel, Skulpturen und Gemälde eindeutige Erscheinungsformen einer Kultur, die weder die Dreidimensionalität des Raumes noch die Unendlichkeit der Zeit kennt:

In der Antike, die das Unendliche in jedem Sinne von sich wies, waren die Zeit auf die Gegenwart, das Ausgedehnte auf den greifbaren Einzelkörper zurückgeführt (Spengler 1972, 996).

Eine tiefgreifende Veränderung, was die Raumauffassung betrifft („Der Körper besitzt Teile, im Raum verlaufen Prozesse“) (Spengler 1972, 389), ergab sich zur Epoche Konstantins und in der Folgezeit. Geschichtsumwandlungen von außerordentlicher Bedeutung - wie die Entdeckung der Tiefe des Raumes in der Spätantike - offenbarten sich durch Umgestaltungen, die damals in Architektur und Kunstwerken stattfanden: Bögen und Kuppeln wurden zunehmend im Bauwesen eingesetzt. Der Innenraum gewann im Übergang vom antiken Tempel zur christlichen Basilika immer mehr an Bedeutung; bei Marmorstatuen erwarb das Auge die Pupille, die vorher nicht modelliert wurde, und der Blick schien in die Ferne zu schauen (Orsucci 2012, 215-314).

Um die Wesenszüge einer historischen Epoche hervorzuheben, ist es nach Spenglers Ansicht vor allem notwendig, Formen und Figuren zu erfassen und zu deuten, und so die Kenntnis einer Kunstgeschichte zu erweitern, die sich - nach Alois Riegl, Josef Strzygowski und Wilhelm Worringer - zunehmend mit Fragen beschäftigt, die die gesamte Geistesgeschichte betreffen.

Um 1920 werden „Gotik und Barock“, wie Erwin Troeltsch bemerkt, „zum Mittelpunkt der historischen Auffassung“ (Troeltsch 1922, 507-508, 650 u. 734). Auch Spengler legt in seinen Untersuchungen besonderen Wert auf die Gotik und 
den Barock, wenn er sich mit der Frage auseinandersetzt, wie in der Moderne die Eroberung des dreidimensionalen Raumes und die Loslösung von den Kanons des Klassizismus erfolgen. Dem Philosophen stehen in diesem Zusammenhang bedeutende Studien zur Verfügung, die es ihm erlauben, die Universalgeschichte aus neuen Blickwinkeln zu betrachten und sich dabei auf Themen und Bezüge zu konzentrieren, die traditionell weitgehend vernachlässigt worden waren. Auf diese Weise erhält er wichtige Hinweise für seine Thesen sowohl aus der Geschichte der europäischen Gartenbaukunst in der Neuzeit als auch aus neuen Studien zur Malerei des 16. und 17. Jahrhunderts.

\section{2}

In seinen Überlegungen zum „faustischen Prinzip“ greift Spengler häufig auf das Werk von Marie Luise Gothein zurück, einer mit dem ,George-Kreis“ verbundenen Schriftstellerin, das sich mit der Geschichte der Gartenkunst (Gothein 1914) befasst (Abb. 1-6 und 8-18).

Da die Antike „keine Perspektive“ besaß, war „auch der Park [...] innerhalb der antiken Künste unmöglich. Es gab in Athen und Rom keine irgendwie bedeutende Gartenkunst. Erst die Kaiserzeit fand an orientalischen Anlagen Geschmack, deren kurze und betonte Abschlüsse jeder Blick auf die erhaltenen Plane offenbart“ (Spengler 1972, 310)ํ․ Erst nach der Renaissance, die für Spengler eine absolut unbedeutende Kulturepoche darstellt, unterliegt die Zeit- und Raumerfahrung einer radikalen Umwandlung: „Der Horizont taucht [...] auf als großes Symbol des grenzenlosen Weltraums, die die sichtbaren Einzeldinge als Zufälle in sich begreift“ (Spengler 1972, 309). Die neue „Formensprache“ durchdringt zwischen dem 16. und 17. Jahrhundert die unterschiedlichsten Gebiete sowohl des gesellschaftlichen Lebens wie auch der Kultur.

In seinem Werk beschreibt Spengler mit besonderer Aufmerksamkeit, wie die Anstrengungen, den unbegrenzten Raum zu symbolisieren („Im Unendlichen liegt der Punkt, in dem die perspektivischen Linien zusammentreffen“) (Spengler 1972, 310), selbst an den Vorbildern zu erkennen sind, die für den Bau von Parks und Gärten zu Beginn der Moderne verwendet wurden.

1 Vgl. Gothein 1, 1914, 55: „Gerade in der klassischen Zeit des hellenischen Volkes, in der die andern bildenden Künste in rascher Entwicklung dem Höchsten zustrebten, hören wir nichts von der Gartenkunst [...]. Eine Erklärung für diese auffallende Lücke in dem griechischen Kulturbilde der großen Zeit finden wir in der Verfassung der Polis. Sie bildet den Rahmen, der das ganze geistige und wirtschaftliche Leben der Hellenen umfaßte, und dieser Rahmen bot gerade in der Zeit seiner höchsten Anspannung für die Entwicklung einer privaten Gartenkunst keinen Raum“. 
Im monarchischen Frankreich des siebzehnten Jahrhunderts, zu einer Zeit, als die ästhetischen Kanons der italienischen Renaissance ihre Bedeutung verloren hatten, fand „die bewußte Gestaltung der Natur im Sinne räumlicher Fernwirkung“ - so heißt es im Untergang des Abendlandes (Spengler 1972, 310) einen angemessenen Ausdruck in der Konzeption von Parkanlagen.

Mit diesen Überlegungen knüpft Spengler - ohne es seinen Lesern zu erklären - an das an, was Marie Luise Gothein, in seiner Monographie geschrieben hatte.

In ihrer Studie hatte die Autorin gezeigt, dass die Gestaltung von Gärten und Parks in den toskanischen Landhäusern des fünfzehnten Jahrhunderts der „freie[n] Heiterkeit der jungen Renaissance“ entsprach, „die die dunklen Schatten höchstens als Hintergrund dulden will“ (Gothein 1, 1914, 219-220).

Auch im darauffolgenden Jahrhundert zeigten die florentinischen MediciVillen in ihrer Außenansicht weiterhin „einen Anblick von Würde und Grazie“, obwohl sie „einen festungsartigen Charakter“ als Hinterlassenschaft einer Tradition mittelalterlichen Ursprungs bewahrten (Gothein 1, 1914, 225-229).

Bei der Gestaltung von Landhaus und Garten - setzt die Verfasserin fort hielten sich die Architekten damals in der Toskana strikt an ein Prinzip von „Ordnung“ und „Symmetrie“. Großes Gewicht wurde auf die „Übereinstimmung der Hauptlinien des Gartenplans mit der Fassade des Hauses“ gelegt, „nach der er sich in Größe und Anordnung der Winkel zu richten habe“. Außerdem war es nach den ästhetischen Kriterien der damaligen Zeit erforderlich, dass ,alle Gartenstücke [...] um das Gebäude herum [...] in gleiche Quadrate eingeteilt und von bequemen breiten Wegen durchschnitten“ seien (Gothein 1, 1914, 232-233, 352 u. 367).

Spengler greift all diese Überlegungen unter dem Begriff der „Übersichtlichkeit“ des Renaissance-Parks auf und fasst sie in einigen Seiten seines Werkes zusammen, in denen auch andere Thesen von Marie Luise Gothein enthalten sind, ohne jedoch explizite Hinweise auf ihre Herkunft:

Der erste Gartentheoretiker des Abendlandes, L. B. Alberti, lehrte denn auch um 1450 schon die Beziehung der Anlage auf das Haus [...], und von seinen Entwürfen bis zu den Parks der Villen Ludovisi und Albani zeigt sich ein immer stärkeres Hervortreten perspektivischer Fernblicke. Frankreich hat dem seit Franz I. die langen Wasserstreifen hinzugefügt (Fontainebleau) (Spengler 1972, 310 -311).

Im sechzehnten Jahrhundert zeichnet sich der französische Park aus, wie Marie Luise Gothein in ihrem Text detailliert dokumentiert, durch die Erhaltung und Umgestaltung „eines [...] mittelalterlichen Motivs des Schloßbaues, des Wassergräbens“. Zur Zeit des Königs Franz I entfaltet sich der Scharfsinn der Architekten, wie man in den Schlössern von Fontainebleau (vgl. Abb.7-9) und Chantilly sehen 
kann, durch die Errichtung einer Vielzahl von Teichen und Kanälen, Brunnen, Wasserfällen und Wasserspielen im Garten. („Noch ist der Grundplan ganz unregelmäßig, die Gartenstücke sind einzeln, fast zufällig hier- und dorthin verstreut, überall aber ist das Wasser als breiter Weiher oder schmaler Kanal auffallend reich vertreten“) (Gothein 2, 1914, 11-13).

Auf diese Weise zeichnet sich der französische Park zwischen dem 16. und 17. Jahrhundert, wie Spengler in Anlehnung an Gothein feststellt, durch das Bemühen aus, jenes Gefühl von Ferne und jene Ausblicke in die Landschaft zu fördern, die das ideale Parkmodell der italienischen Renaissance unbedingt vermeiden wollte:

Das bedeutsamste Element im abendländischen Gartenbilde ist mithin der point de vue der großen Rokokoparks, auf den sich ihre Alleen und beschnittenen Laubgänge öffnen und durch den sich der Blick in weite schwindende Fernen verliert (Spengler 1972, 311). ${ }^{2}$

Die Umgebung des Schlosses musste, wie es zu Beginn der Neuzeit erforderlich war, jenen „Blick ins Grenzlose“ anregen, der „dem Auge [...] den Sinn der Natur erschließt“ und die „faustische Sehnsucht“ befriedigt („Wir waren es und nicht die Hellenen, nicht die Menschen der Hochrenaissance, welche die unbegrenzte Fernsichten vom Hochgebirge aus schätzen und suchten [...]. Man will allein mit dem unendlichen Raume sein“) (Spengler 1972, 311). Die Herausbildung eines „faustischen Willens zum Unendlichen“, der das bisherige „apollinische Lebensgefühl“ verdrängt (Spengler 1972, 993), manifestiert sich also in den architektonischen Formen der Landschlösser und Parks des 17. Jahrhunderts in einer sehr deutlich erkennbaren Weise.

Spengler schreibt weiter darüber:

Dies Symbol bis zum Äußersten zu steigern, war die große Tat der nordfranzösischen Gartenbaumeister, nach der epochemachenden Schöpfung Fouquets in Vaux-le-Vicomte vor allem Lenôtres. Man vergleiche den Renaissancepark der mediceischen Zeit mit seiner Übersichtlichkeit, seiner heitren Nähe und Rundung, dem Kommensurablen seiner Linien, Umrisse und Baumgruppen, mit diesem geheimen Zug in die Ferne, der alle Wasserkünste, Statuenreihen, Gebüsche, Labyrinthe bewegt [...] (Spengler 1972, 311).

Und weiter:

Ein Renaissancepark ist für den Sommer und den Mittag gedacht. Er ist zeitlos. Nichts in seiner Formensprache erinnert an Vergänglichkeit. Erst die Perspektive ruft die Ahnung von etwas Vergehendem, Flüchtigem, Letztem wach (Spengler 1972, 311).

2 Über den point de vue, vgl. Gothein 2, 1914, 132 u. 162. 
Spenglers Textpassage greift Seiten von Gothein auf, in denen von Nicolas Fouquet, Mazarins Finanzminister, und von dem Schloss von Vaux-le-Vicomte, an dem auch André Le Nôtre für den Entwurf des Gartens beteiligt war, die Rede ist. Der Garten von Vaux-le-Vicomte sowie der nachfolgende Park von Versailles zeugen - so Gothein - vom „Geist der Disziplin, der festen, klar übersichtlichen Regel, der Proportion“, betonen aber auch nachdrücklich „das ungestüme und immer wachsende Verlangen nach 'variétè', nach Abwechslung“ (Gothein 2, 1914, $129-132)$.

André Le Nôtre war dann von 1662-1663 an für die Gestaltung des Versailler Parks verantwortlich; und sein Projekt, wie Gothein ausführlich dokumentiert, fand seinen Höhepunkt bei der Ausgrabung des ,großen Kanals, eines Werkes, bei dem Le Nôtre auch nicht einen Augenblick gezweifelt hat, es gleich in seiner gewaltigen Größe und unvergleichlich imposanten Wirkung festzulegen“. Tatsächlich hat der Eure-Kanal im Zentrum des Parks von Versailles die Wirkung, „dem ganzen Gartenbilde eine Geschlossenheit und zugleich Weite“ zu verleihen, „wie es nur ein mächtiger bewegter Wasserspiegel vermag“ (Gothein 2, 1914, 144).

Die Art und Weise, wie Spengler die Ergebnisse der Untersuchung von Marie Luise Gothein aufgreift und in sein Werk einfügt, verdeutlicht die Akribie und die Schärfe des Philosophen bei der Auswahl der Materialien und der Dokumentation, die in seine Überlegungen mit einbezogen werden sollen. Sein ,historischer Blick', seine Fähigkeit, ,Bilder' zum Sprechen zu bringen, ist daher sehr oft das Ergebnis - auch wenn die Kritik dies noch heute oft ignoriert - eingehender Fachstudien, die vor allem Disziplinen wie die Altertumswissenschaft und die Kunstgeschichte betreffen.

\section{3}

Spengler will zeigen, wie sämtliche Bilder und Kunstformen, die eine bestimmte Epoche prägen, die wesentlichen Züge einer umfassenden „Lebenserfahrung“ (Spengler 1972, 134 u. 153) und eine besondere Vorstellung von Raum und Zeit zum Ausdruck bringen. Um den Ablauf der Weltgeschichte $\mathrm{zu}$ ermitteln und $\mathrm{zu}$ erläutern, ist es daher notwendig, eine „Morphologie der Geschichte“ zu erarbeiten, die darauf abzielt, „die Formensprache der abendländischen Kultur“ (Spengler 1972, 300) in all ihren komplizierten Manifestationen zu verstehen.

Auch die Vorliebe für gewisse Farben bedeutet sowohl im klassischen Griechenland als auch im siebzehnten Jahrhundert die Bindung an bestimmte „Ursymbole“, in denen die Gesamtheit einer Weltsicht und die Affirmation oder Negation der Unendlichkeit von Raum und Zeit zusammengefasst und verdichtet sind. 
Um seine Ansichten zu erhärten, geht Spengler in einem wichtigen Abschnitt seines Werkes auf den symbolischen Wert der Farben in der klassischen Welt ein. Seine Ausführungen unterstreichen in diesem Sinn die enge Verbindung, die zwischen chromatischer Sensibilität und Weltanschauungen besteht.

„Die antike Malerei strengen Stils beschränkte ihre Palette auf gelb, rot, schwarz und weiß“ (Spengler 1972, 317). In ihren Fresken zeigten die Griechen - so Spengler - eine tiefe Abneigung gegen die Farbtöne von Blau und Grün und ließen „erst bei den grüngelben und bläulichroten Tönen die Skala der erlaubten Farben beginnen“ (Spengler 1972, 317). Dieser Hang bestätigt ein grundlegendes Merkmal der antiken, „euklidischen“ Weltanschauung, nämlich das Unvermögen, den dreidimensionalen Raum zu ,erblicken` und zu erfassen:

Blau und Grün sind die Farben des Himmels, des Meeres, der fruchtbaren Ebene, der Schatten an südlichen Mittagen, des Abends und der entfernten Gebirge. Sie sind wesentlich atmosphärische, nicht gegenständliche Farben [...]; sie entkörpern und rufen die Eindrücke des Weiten, Fernen und Grenzenlosen hervor (Spengler 1972, 317).

In der Malerei von Polygnotos aus Thasos und im „strengen Freskogemälde attischen Stils“ ist die Palette der akzeptierten chromatischen Töne sehr beschränkt:

Gelb und Rot, die antiken Farben, sind die der Materie, der Nähe und der Sprache des Blutes. Rot ist die eigentliche Farbe der Geschlechtlichkeit [...]. Sie steht dem Symbol des Phallus und also der Statue und der dorischen Säule - am nächsten, wie andrerseits ein reines Blau den Mantel der Madonna verklärt (Spengler 1972, 318).

Gelb und Rot werden verwendet, um die „Linearperspektive“, nicht die „Luftperspektive“ anschaulich zu machen: Sie sind „polytheistische Farben“, die dazu dienen, Körpern und Oberflächen zu modellieren und Allem Form zu geben, was in den Bereich „des Vordergrundes [...], des naiven Vorsichhinlebens [...], des punktförmigen Daseins“ fällt (Spengler 1972, 318).

Blau und Grün sind hingegen „monotheistische Farben“ und dienen dazu, die „Luftperspektive“ darzustellen: Sie sind Symbole „der Einsamkeit, der Sorge, der Beziehung des Augenblicks auf Vergangenheit und Zukunft“ (Spengler 1972, 318). Es sind genau diese Farben, die das Auge von allem ablenken, was in die Sphäre des Begrenzten, Körperlichen und Greifbaren fällt:

Das Blau, [...] eine perspektivische Farbe, steht immer in Beziehung zum Dunklen, Lichtlosen, Unwirklichen. Es dringt nicht ein, sondern zieht in die Ferne. 'Ein reizendes Nichts', hat es Goethe in seiner Farbenlehre genannt. Blau und Grün sind transzendente, geistige, unsinnliche Farben (Spengler 1972, 318). 
Die Farben zeichnen sich daher durch die von ihnen suggerierte „Idee des Raumes“ aus, die wiederum mit einer bestimmten Art und Weise des Verständnisses des Zeitablaufs verbunden ist. Verschiedene Epochen und Traditionen unterscheiden sich - so Spengler - durch die ,evokative“ Kraft bestimmter Farbtöne. All dies bestätigt, dass sich in einem Übergangszeitalter nicht nur die sozialen Verhältnisse, die Denkweisen und Bräuche verändern, sondern auch die Art und Weise, wie Farben wahrgenommen werden.

\section{4}

Die Spätantike - die „magische Welt“, deren Bedeutung von Spengler immer wieder unterstrichen wird - will sich in ihren künstlerischen Formen von der tyrannischen Herrschaft des ,taktilen“ Raumes und der ,stofflichen Wesenheit des Körpers“ (Spengler 1972, 321) befreien. Der neue „Kunstwollen“, der die Darstellung einer unbegrenzten Räumlichkeit anstrebt, erfindet neue Ausdrucksformen und versucht, neue chromatische Effekte zu erzeugen, die es dem Betrachter ermöglichen, über „die sinnliche Oberfläche der Dinge“ (Spengler 1972, 323) hinauszugehen:

\footnotetext{
Die arabische Kunst hat das magische Weltgefühl durch den Goldgrund ihrer Mosaiken und Tafelbilder zum Ausdruck gebracht. Man lernt seine verwirrend märchenhafte Wirkung und mithin seine symbolische Absicht aus den Mosaiken von Ravenna [...]; die magische [Kultur] empfand alles Geschehende als Ausdruck rätselhafter, die Welthöhle mit ihrer geistigen Substanz durchdringenden Mächte - und sie schloß die Szene durch einen Goldgrund ab, das heißt durch ein Mittel, das jenseits alles Farbig-Natürlichen steht. Gold ist überhaupt keine Farbe (Spengler 1972, 320).
}

Zur Zeit der Entstehung des Oströmischen Reiches zersetzt „das Symbol [...] des Goldgrundes“ der Fresken und Mosaiken, d.h. die Magie des „rätselhaft hieratischen Hintergrundes“, die Realität der sinnlichen Welt und macht die Festigkeit von Körpern und Objekten illusorisch: „Das leuchtende Gold nimmt der Szene, dem Leben, den Körpern ihr handgreifliches Sein“ (Spengler 1972, 321).

Mit diesen Überlegungen hebt Spengler erneut die ,Evokationskraft` der Farben hervor, ihre enge Verbindung mit komplexen Verkettungen von Vorstellungen. Dank des goldenen Hintergrunds der Fresken und Mosaiken, ist „ein punktförmiges Jetzt“ (Spengler 1972, 323) nicht mehr das vorherrschende Prinzip, und es beginnt, sich ein neues „Formgefühl“ Bahn zu brechen.

Einen neuen Stützpunkt bietet dem Philosophen in diesem Fall die Monographie von Alois Riegl, Die spätrömische Kunst-Industrie (1901), in der es heißt: 
In diesem Lichte betrachtet erscheint auch der Goldgrund der byzantinischen Mosaiken als ein Fortschritt gegenüber dem blauen Luftgrund der römischen Mosaiken. Denn dieser ist stets die Ebene geblieben, aus welcher die Einzeldinge, durch verschiedene Färbung (Polychromie) kenntlich, herauswachsen, wie sie sich eben unmittelbar unserem Gesichtssinne, unter möglichstem Ausschluss jeder Reflexion darstellt, mag sich auch allmählich zwischen die Vorderfigur und die Grundebene der sogenannte Hintergrund eingeschoben haben. Der Goldgrund der byzantinischen Mosaiken hingegen, der den Hintergrund im allgemeinen ausschließt und damit zunächst einen Rückschritt zu bezeichnen scheint, ist nicht mehr Grundebene, sondern idealer Raumgrund, welchen die abendländischen Völker in der Folge mit realen Dingen bevölkern und in die unendliche Tiefe ausdehnen konnten. Die Antike kannte Einheit und Unendlichkeit nur in der Ebene, die neuere Kunst hingegen sucht beide im Tiefraume; die spätrömische Kunst steht zwischen beiden mitten inne, denn sie hat die Einzelfigur aus der Ebene losgelöst und damit die Fiction der allgebärenden Grundebene überwunden, aber sie anerkennt den Raum - darin noch immer der Antike folgend - nur als geschlossene (cubische) Einzelform und noch nicht als unendlichen Freiraum (Riegl 1901, 8).

Diese Überlegungen sind in dem Werk von Riegl keineswegs marginal. Die Aufgabe seiner gesamten Untersuchung besteht darin, eine systematische Sammlung von Kunstwerken aus der Spätantike anzubieten, die die „gleiche Emanzipation des Grundes zur Raumbedeutung“ aufzeigen, „wie wir sie im Relief von den ravennatischen Sarkophagen an beobachtet hatten, und wie sie sich später im Goldgrunde der Mosaiken aussprich“ (Riegl 1901, 144).

In der Spätantike - das ist das Ergebnis seiner Ausführungen - wird die Figur aus dem Hintergrund aufgelöst: Und gerade diese „Loslösung der Einzelform aus der Ebene“ (Riegl 1901, 10) stellt den ersten Moment des Prozesses dar, der in späteren Epochen zur Entdeckung des dreidimensionalen Raumes führen wird.

\section{5}

Eine bestimmte geschichtliche Periode offenbart in den künstlerischen Formen und Gestalten, die sie hervorbringt und in denen sie sich identifiziert, ihren eigenen „metaphysischen Hang“, der sich im Laufe der Zeit auch in den Wandlungen manifestiert, die das „Verhältnis zwischen der Idee des Raumes und dem Sinn der Farbe“ (Spengler 1972, 319) erfährt.

Riegl hatte in dem von Spengler aufmerksam gelesenen Werk gezeigt, dass die klassische Antike lediglich „die taktische Wahrheit der Einzelobjecte [...] ohne Rücksicht auf den Raum“ kannte, während erst in der Neuzeit „die optische Wahrheit der Dinge im Räume“ in künstlerischen Werken Sichtbarkeit gewann (Riegl 1901, 133). 
Von der Unterscheidung zwischen der „Darstellung der Einzelform in der Ebene“ und der „Darstellung der Einzelform im Raum“ (Riegl 1901, 9) ausgehend, hebt Spengler hervor, dass die Herausbildung eines neuen „Formgefühls“, dem es gelingt, die Herrschaft des „punktförmigen Jetzt“ niederzureißen, in der Neuzeit eine neue, in früheren Epochen unbekannte Farbempfindlichkeit erzeugt: „Als die ersten ,wirklichen' Hintergründe in der frühen Gotik auftauchen, mit blaugrünem Himmel, weitem Horizont und Tiefenperspektive, wirken sie zunächst profan, weltlich“ (Spengler 1972, 321).

Unter diesem Gesichtspunkt gibt es keine Kontinuität zwischen der Neuzeit und der klassischen Welt:

Da der unendliche Raum für das antike Lebensgefühl ein vollkommenes Nichts ist, so würden Blau und Grün mit ihrer entwirklichenden und Fernen schaffenden Kraft die Alleinherrschaft des Vordergrundes, der vereinzelten Körper und damit den eigentlichen Sinn apollinischer Kunstwerke in Frage gestellt haben (Spengler 1972, 319-320).

In der modernen Malerei, vom Ende des fünfzehnten Jahrhunderts an, kommt eine entschiedene Abneigung gegen ,die alten Vordergrundfarben, Gelb und Rot - die antiken Töne“ (Spengler 1972, 325) zum Ausdruck. So Spengler:

Die bedeutendste Verwendung eines düsteren Grüns als der Farbe des Schicksals findet sich bei Grünewald, dessen Nächte von einer unbeschreiblichen Mächtigkeit des Raumes nur von Rembrandt noch erreicht werden (Spengler 1972, 319).

In der bedeutendsten Malerei des siebzehnten Jahrhunderts gewinnen neue chromatische Effekte immer mehr an Gewicht. In den Gemälden dieser Epoche tauchen häufig verschiedene Brauntöne auf, d.h. Schattierungen einer Farbe, die im „Kampf des Raumes gegen das Stoffliche“ eine zentrale Rolle spielt, und die „das greifbare Dasein der sinnlichen Welt - der Welt des Augenblicks und der Vordergründe - endgültig in atmosphärischen Schein“ auflöst (Spengler 1972, 324). Mittels der eingeführten Änderungen in der Farbpalette ist es schließlich möglich, ,eine reine formvolle Unendlichkeit“ in den Gemälden zu veranschaulichen (Spengler 1972, 324-327):

Alle die grünlichbraunen, silbrigen, feuchtbraunen, tiefgoldigen Töne, die bei Giorgione in prachtvollen Spielarten erscheinen, bei den großen Niederländern immer kühner werden und sich gegen Ende des 18. Jahrhunderts verlieren, entkleiden die Natur ihrer greifbaren Wirklichkeit (Spengler 1972, 325). 
Selbst Rembrandts Malerei schätzt und verwendet häufig „dies rätselhafte Braun [...], das aus dem tiefen Leuchten mancher gotischen Kirchenfenster, aus der Dämmerung hochgewölbter Dome stammt“ (Spengler 1972, 326).

\section{6}

Die Ausführungen zur französischen Gartenkunst im siebzehnten Jahrhundert finden bei Spengler eine genaue Entsprechung in den Seiten, die der gotischen Kathedrale gewidmet sind, d.h. einer architektonischen Form, die eine drastische Opposition zu dem in der griechisch-römischen Welt maßgebenden Prinzip der „Ausdehnung“ darstellt („Da Stoffliche, sichtbare Begrenzte, Greifbare, unmittelbar Gegenwärtige“) (Spengler 1972, 229). Tatsächlich erscheint der dorische Tempel, anders als die Kathedrale, als ein organischer Körper, der sich von einem Zentrum aus entwickelt:

In dem Steinkörper des antiken Tempels [...] befindet sich keine einzige gerade Linie. Alle Treppenstufen haben eine leise Schwingung nach außen, und zwar jede von anderem Grad. Die Giebel, der Dachfirst, die Seiten sind geschwungen. Jede Säule hat eine leichte Schwellung; keine steht vollkommen senkrecht [...] So bekommt der ganze Körper etwas geheimnisvoll um einen Mittelpunkt Kreisendes. Die Krümmungen sind so fein, daß sie dem Auge gewissermaßen nicht sichtbar, nur fühlbar sind. Eben dadurch aber wird die Tiefenrichtung aufgehoben. Der gotische Stil strebt, der dorische schwingt. Der Innenraum der Dome zieht mit Urgewalt empor und in die Ferne; der Tempel ist in majestätischer Ruhe hingelagert (Spengler 1972, 229-230).

An einer anderen Stelle kehrt Spengler wieder zum gleichen Thema zurück:

Der Dom [...] ist nicht nur Kunst, sondern auch die einzige, durch die nichts nachgeahmt wird. Sie allein ist ganz Spannung verharrender Formen, ganz dreidimensionale Logik, die sich in Kanten, Flächen und Räumen ausspricht (Spengler 1972, 251).

In dem „aufstrebenden Mittelschiff der Dome“ feiert der „Tiefendrang der faustischen Seele“, der in dem „körperhaften dorischen Tempel“ keine adäquate Ausdrucksform fand (Spengler 1972, 230 u. 516), seinen Triumph.

All diese Überlegungen sind präzise Umschreibungen dessen, was Spengler in Wilhelm Worringers Buch Formprobleme der Gotik (1912) findet, in dem die These vertreten wird, dass eine gotische Kathedrale die Verneinung ,jeder Stilerscheinung“ ist, „die ein organisches Leben zeigt“ (Worringer 1912, 85).

Dank „dem gotischen Höhentrieb, diesem Drängen nach einer unendlichen immateriellen Bewegtheit“, wird laut Worringer die „Emanzipation vom Körper, d.h. von der ganzen sinnlichen Bauauffassung der antiken Tradition“ erreicht 
(Worringer 1912, 86). In der klassischen Welt hat die Baukunst ausnahmslos den Charakter einer „reinen Tektonik ohne raumschaffende Absicht“. Die Antike tritt nämlich ,an den Raum [...] mit organischen Gestaltungszielen heran und sucht ihn gleichsam wie etwas Organisch-Lebendiges, ja wie etwas Körperliches zu behandeln“ (Worringer 1912, 87-88).

Beim Errichten einer Kirche, so Worringer, gelingt es dem „unsinnlichen nordischen Kunstempfinden“, ein abstraktes Spiel von „Formenergien“ (Worringer 1912, 90 u. 95) sichtbar zu machen:

\footnotetext{
Die altchristliche Basilika hatte ihr Ziel im Altar. Mit energischen Linienzwang leitete sie die ganze Aufmerksamkeit auf diesen Endpunkt der Bewegung, den Altar, hin. Auch die gotische Kathedrale kennt einen Linienzwang. Aber sein Ziel ist ein anderes. Es ist jene irreale Linie in verschwindender Höhe, nach der alle ihre Kräfte, all ihre Bewegtheit orientiert sind. Die Basilika hatte ein Bestimmtes Ziel, die gotische Kathedrale ein unbestimmtes. Ihre Bewegung verklingt im Unendlichen (Worringer 1912, 100).
}

In der gotischen Baukunst, nach Worringer, „tritt [...] der Uebergang vom Sinnlichen zum Uebersinnlichen ein, d.h. die Bauglieder verlieren immer mehr ihren körperlich materiellen Gehalt und werden zu abstrakten Ausdrucksträgern“ (Worringer 1912, 107).

Dank Worringer setzt Spengler also ein neues Element in seinem Fresko der Gegensätze zwischen der Starrheit der „antiken Kultur“, in der „das leibhaft Greifbare [...] vorwaltet“, und der Dynamik der Moderne („dort ein Sein, hier der Wille [...], der Raum, die Kraft“) (Spengler 1972, 516).

Spenglers Werk, das in den frühen 20er Jahren eine wahre „Sensation“ wurde, die plötzlich „wie ein Meteor auftauchte und wieder verschwand“ (Heussi 1932, 30), wird oft als der Text eines ,journalistischen Propheten“ angesehen, wie Ernst Bloch 1922 schrieb (Schroeter 1922, 9).

Beurteilungen dieser Art werden einem Autor nicht gerecht, der mit bemerkenswerter „Virtuosität“ seine „Morphologie der Geschichte“ entwirft und das aus der Krise und Desorientierung der Zeit hervorgehende Fachwissen (Philologie, Altertumswissenschaft, Religionsgeschichte, Ästhetik) im Detail kennt und in eine „große, oft geniale Zusammenschau“ umsetzt (Haering 1921, 7).

Es ist für Spengler offensichtlich, dass Historiker und Kulturphilosophen, wenn sie die entscheidenden Züge einer geschichtlichen Epoche herausarbeiten wollen, nicht auf die Betrachtung dessen beschränken dürfen, was sich auf der ,erhabenen' Ebene der Literatur, der Philosophien und Ideologien einer bestimmten Zeitspanne befindet. Seiner Ansicht nach sind es Elemente, die in der historischen Interpretation oft vernachlässigt werden (die zu einer gegebenen Zeit vorherrschenden Modelle in der Ornamentik und in der Architektur, das zähe Festhalten einer Epoche an gewissen Farbtönen, der Wandel in der Art und Weise 
der Gestaltung von Parkanlagen), die die „Formensprachen“ und die „Symbole“ enthalten, die eine ganze Kultur in ihren Grundzügen definieren.

Aus dieser Forschungsperspektive ist es ist es keineswegs merkwürdig, so Spengler, dass „die edle Romanik Westfalens und Sachsens (Hildesheim, Gernrode, Paulinzella, Paderborn), Südfrankreichs und der Normannen (Norwich, Peterborough in England) [...] mit einer unbeschreiblichen inneren Wucht und Würde den ganzen Sinn der Welt in eine Linie, ein Kapitäl, einen Bogen zu legen vermochte“ (Spengler 1972, 252-253) ${ }^{3}$.

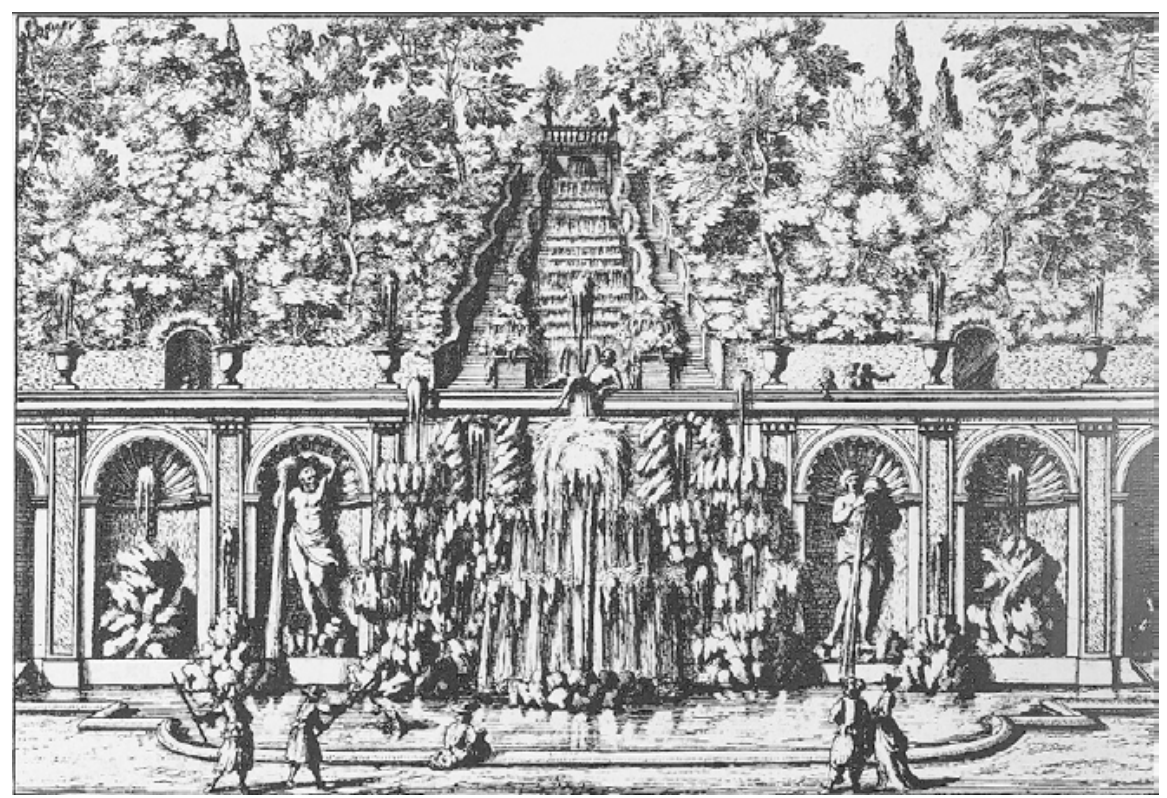

Abb. 1: Villa Ludovisi Frascati, die Wasserkunst. Stich von Venturini. In: Marie Luise Gothein (1914), Geschichte der Gartenkunst, Jena: Diederichs, Bd. I, p. 338, Abb. 249.

3 In diesem Passus fasst Spengler zusammen, was er in verschiedenen Abschnitten von Dehios Buch (1919) findet. 


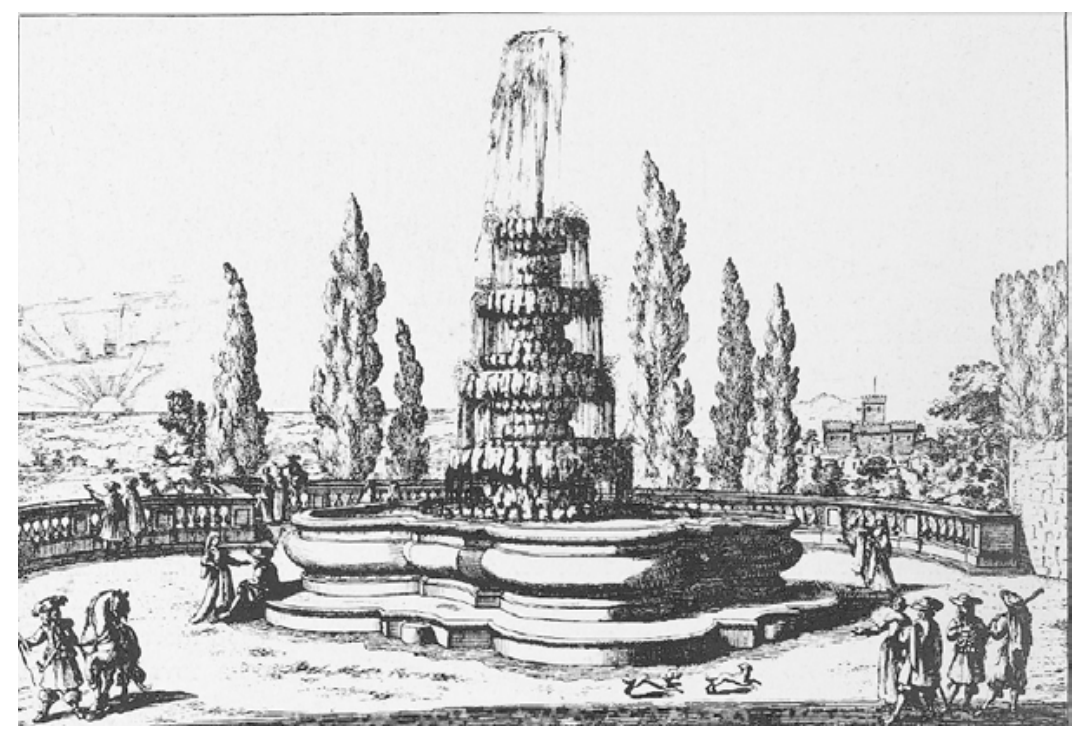

Abb. 2: Villa Ludovisi, Brunnen auf der Palastterrasse. Stich von Falda. In: Marie Luise Gothein (1914), Geschichte der Gartenkunst, Jena: Diederichs, Bd. I, p. 340, Abb. 252.

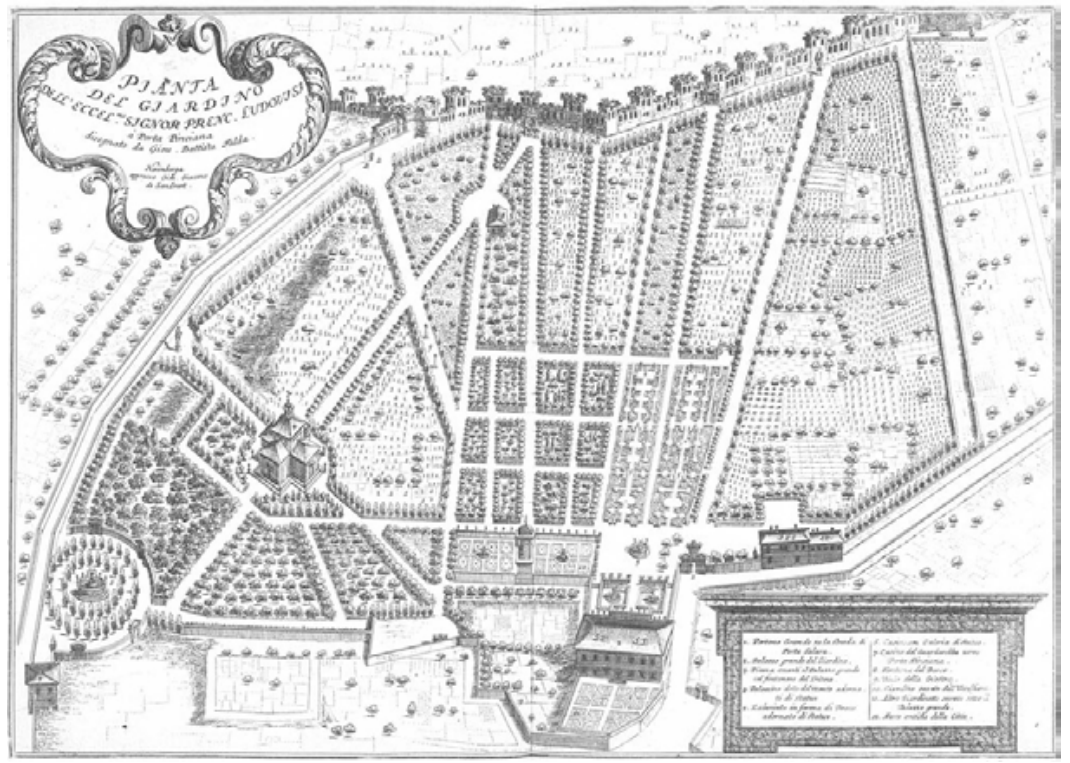

Abb. 3: Villa Ludovisi, Rom, Gesamtplan. Stich von Falda. In: Marie Luise Gothein (1914), Geschichte der Gartenkunst, Jena: Diederichs, Bd. I, p. 351, Abb. 263. 


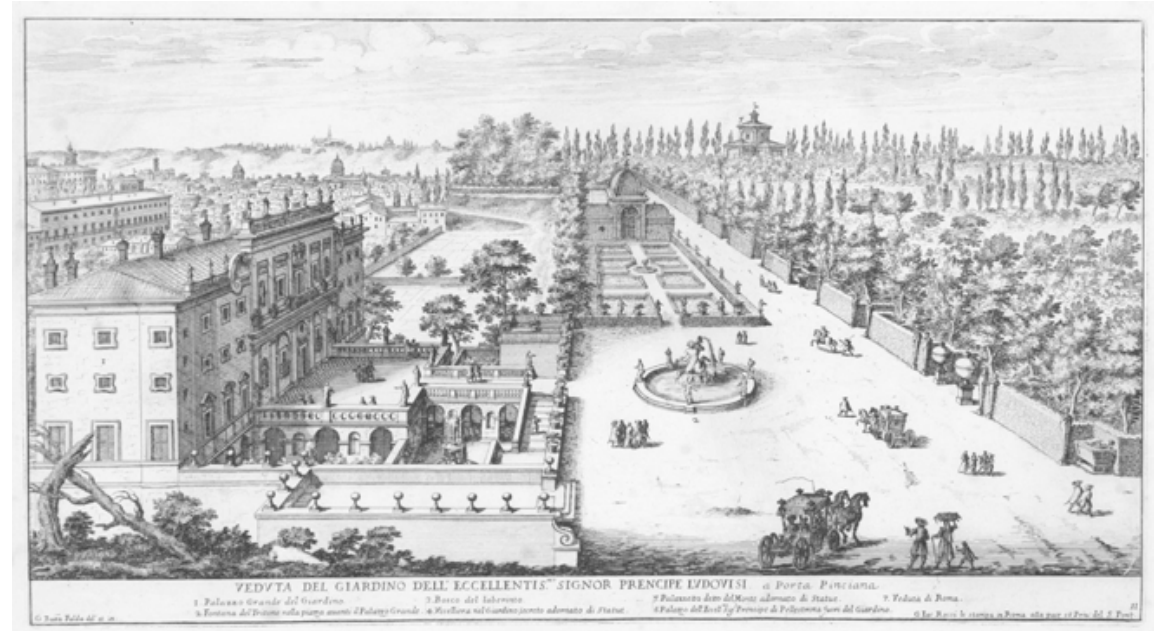

Abb. 4: Villa Ludovisi, Rom, Blick in den Garten. Stich von Falda, Roma: Gian Giacomo de Rossi, ca. 1677-1683. Repr. Nürnberg ca. 1685. Auch in: Marie Luise Gothein (1914), Geschichte der Gartenkunst, Jena: Diederichs, Bd. I, p. 354, Abb. 265).

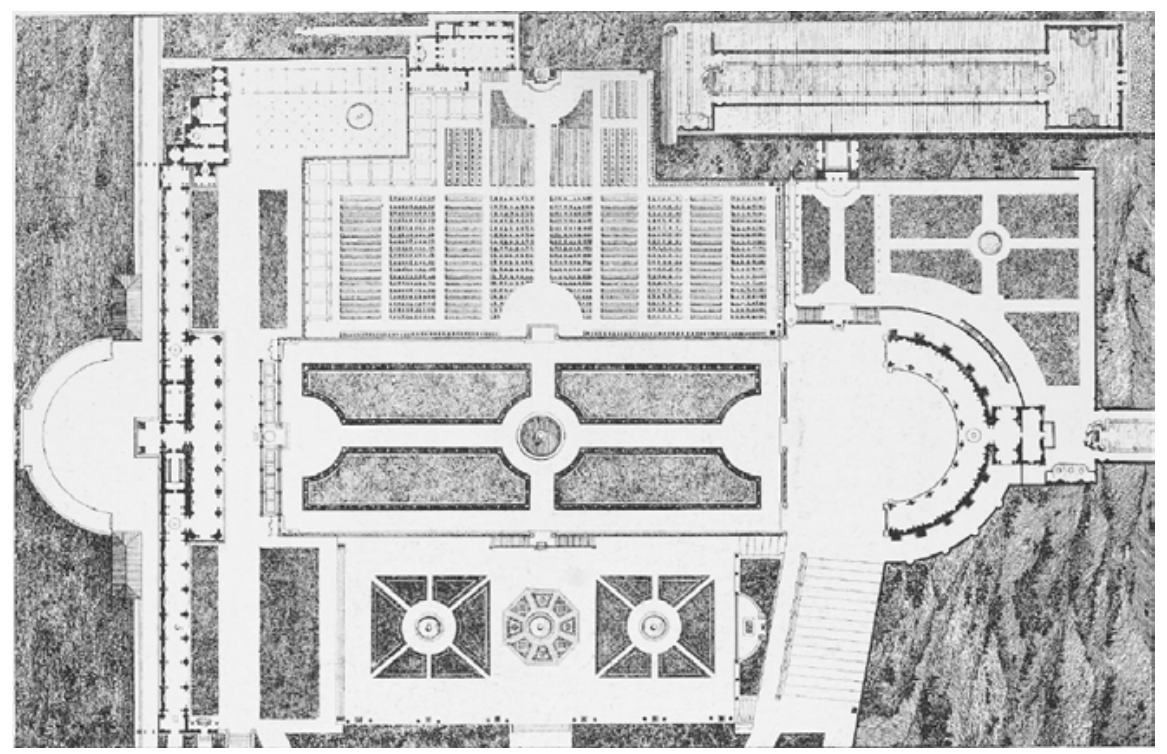

Abb. 5: Villa Albani, Rom, Grundriß des Gartens zwischen Kasino und Kaffeehaus ohne den seitlichen Park. Nach Percier et Fontaine. In: Marie Luise Gothein (1914), Geschichte der Gartenkunst, Jena: Diederichs, Bd. I, p. 363, Abb. 276. 


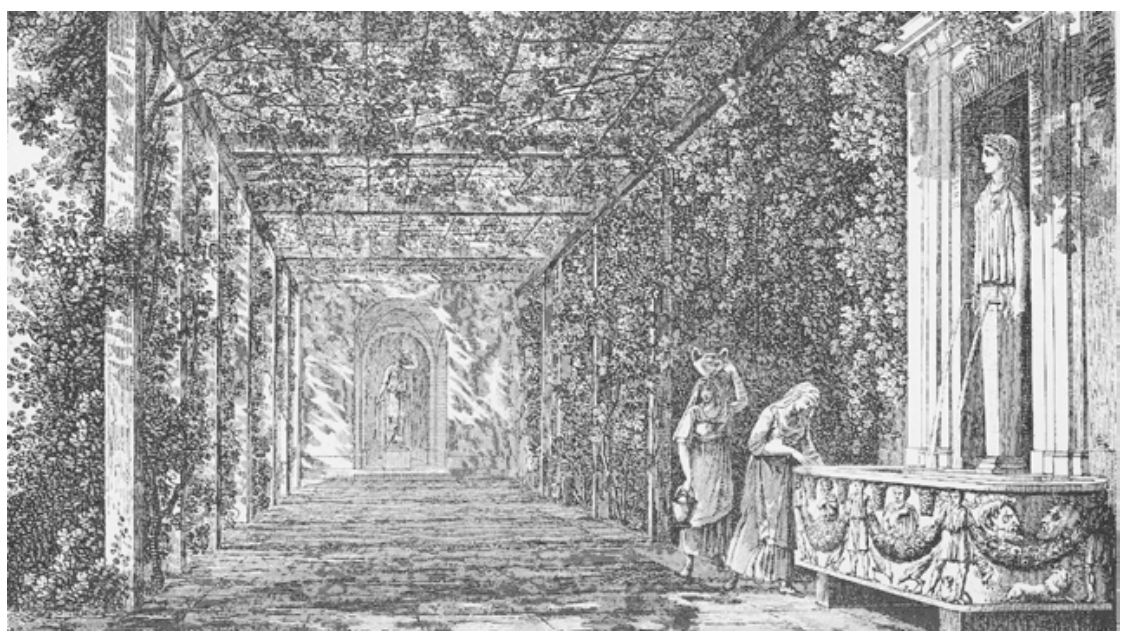

Abb. 6: Villa Albani, Laubengang. Nach Percier et Fontaine, Les plus celebres Maisons de Plaisance de Rome. Nach Percier et Fontaine. In: Marie Luise Gothein (1914), Geschichte der Gartenkunst, Jena: Diederichs, Bd. I, p. 368, Abb. 281.

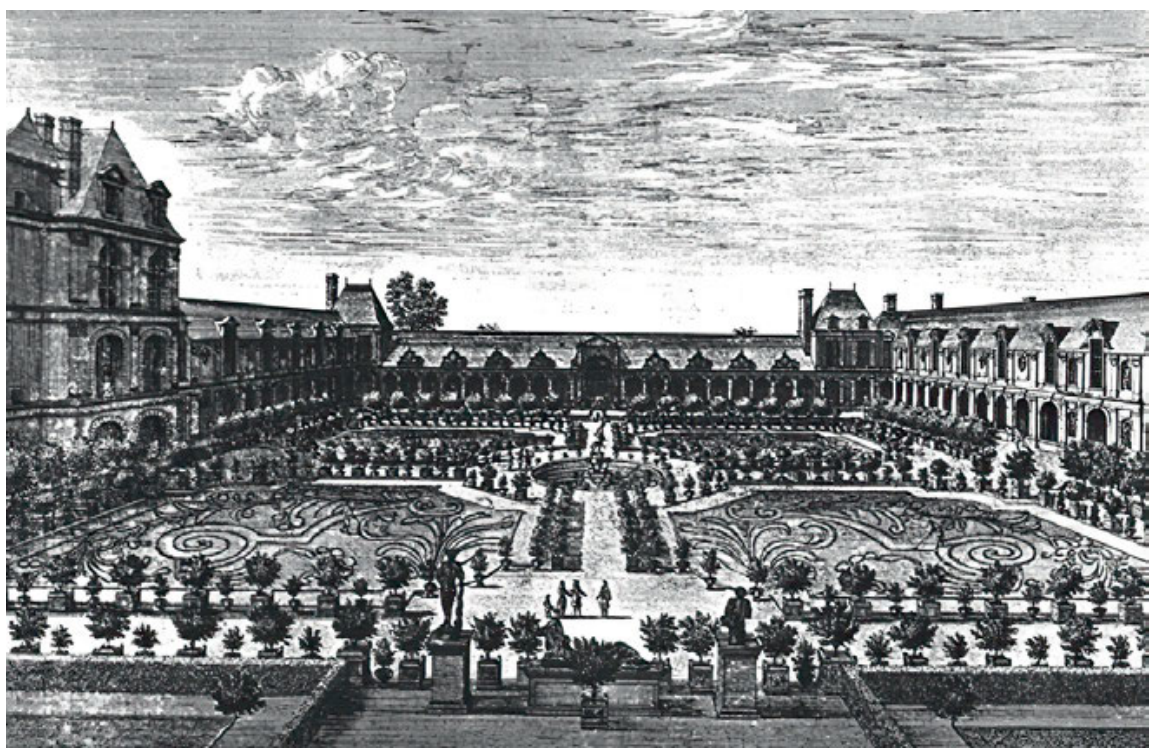

Abb. 7: Fontainebleau, die Orangerie. Stich von Israel Silvestre. In: Marie Luise Gothein (1914), Geschichte der Gartenkunst, Jena: Diederichs, Bd. II, p. 39, Abb. 337. 


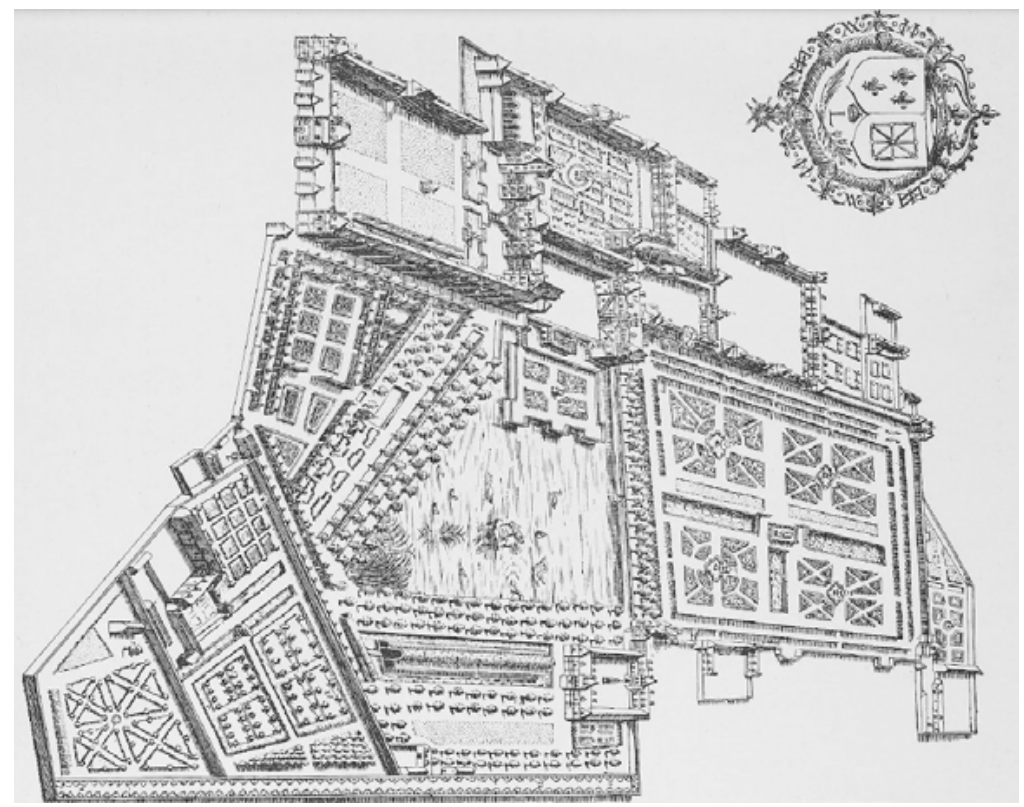

Abb. 8: Fontainebleau unter Heinrich IV. Stich von Furttenbach. In: Marie Luise Gothein (1914), Geschichte der Gartenkunst, Jena: Diederichs, Bd. II, p. 41, Abb. 338.

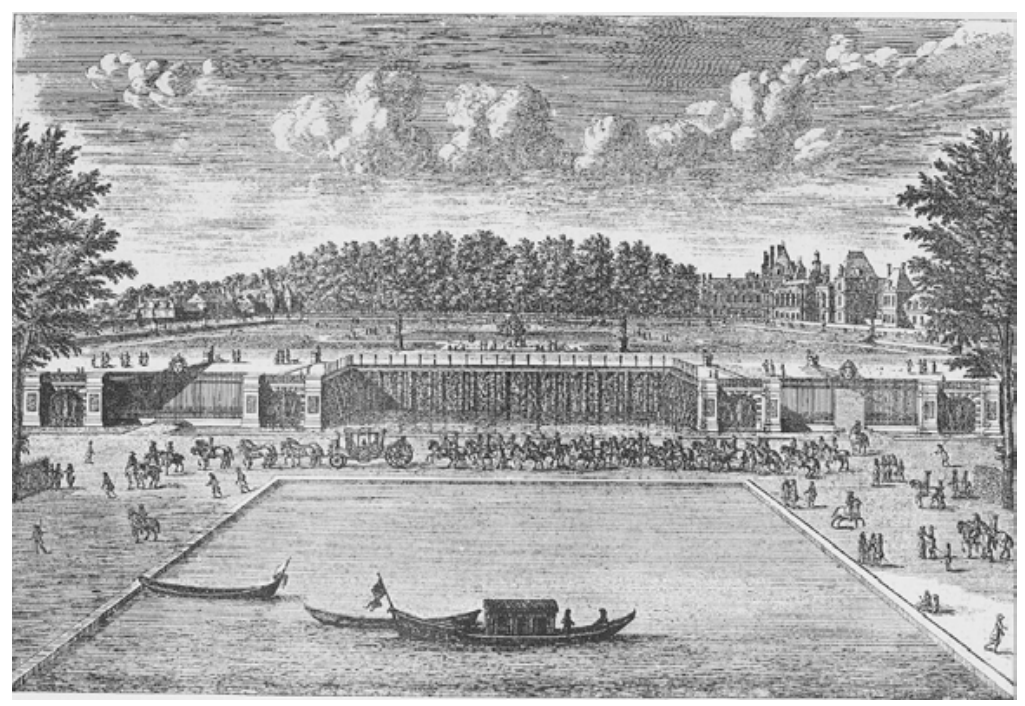

Abb. 9: Fontainebleau von der Seite des großen Kanals. In: Marie Luise Gothein (1914), Geschichte der Gartenkunst, Jena: Diederichs, Bd. II, p. 181, Abb. 431. 


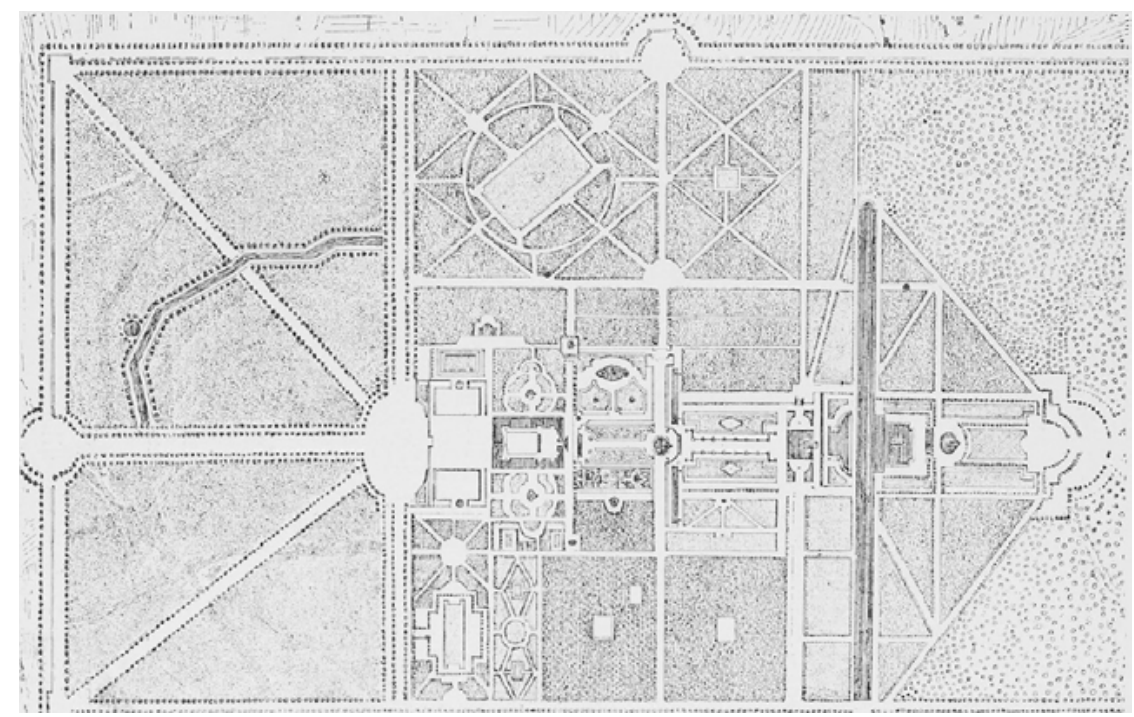

Abb. 10: Vaux-le-Vicompte, Grundplan. Stich von Israel Silvestre. In: Marie Luise Gothein (1914), Geschichte der Gartenkunst, Jena: Diederichs, Bd. II, p. 131, Abb. 392.

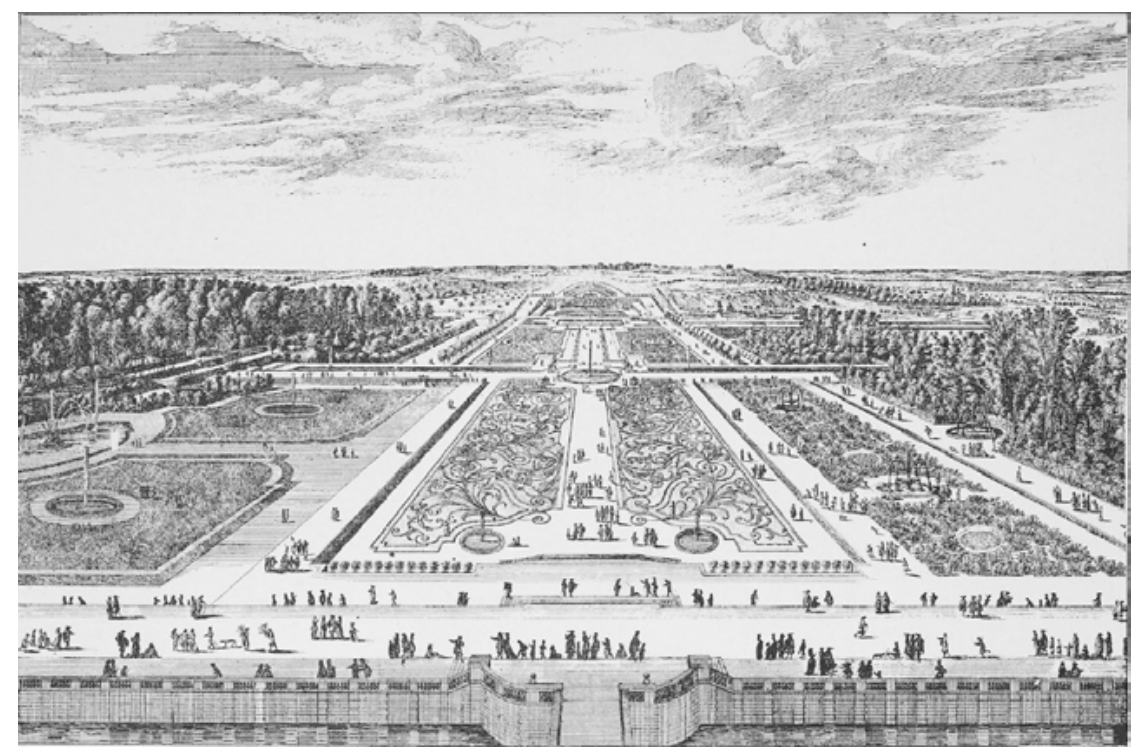

Abb. 11: Vaux-le-Vicompte, Blick von der Schloßterrasse über den Garten. Stich von I. Silvestre. In: Marie Luise Gothein (1914), Geschichte der Gartenkunst, Jena: Diederichs, Bd. II, p. 133, Abb. 393. 


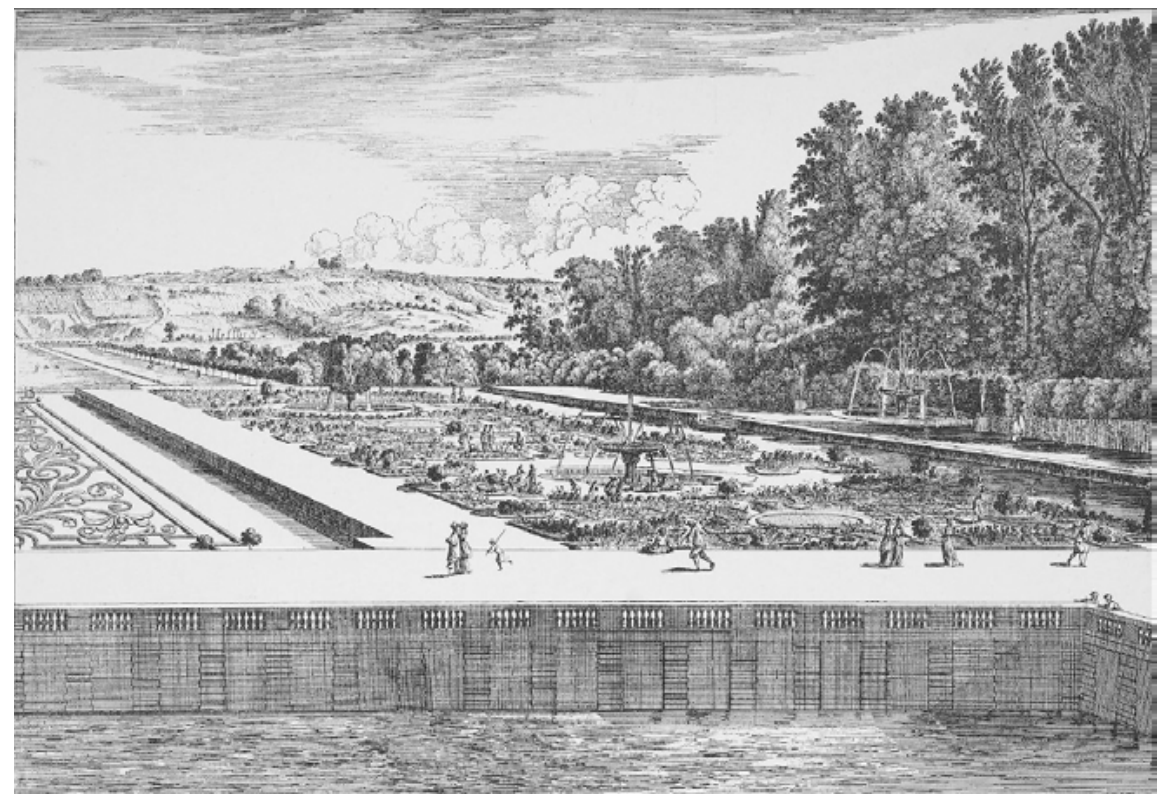

Abb. 12: Vaux-le-Vicompte, Blumenparterre zur Seite. Stich von I. Silvestre. In: Marie Luise Gothein (1914), Geschichte der Gartenkunst, Jena: Diederichs, Bd. II, p. 135, Abb. 394.

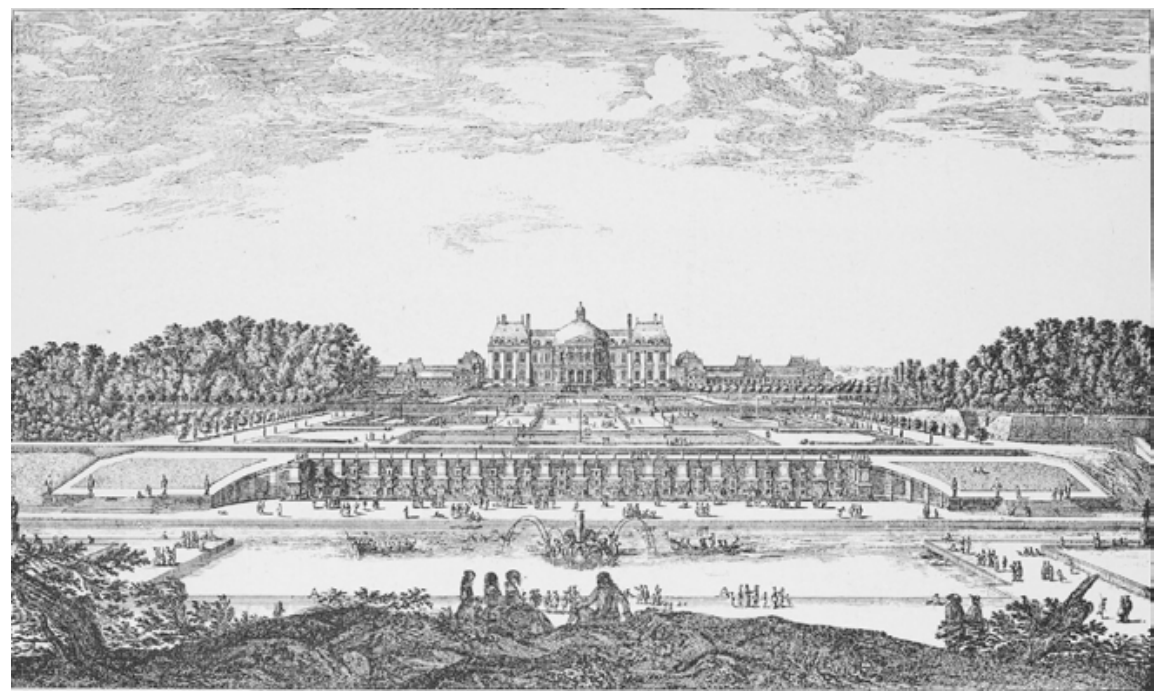

Abb. 13: Vaux-le-Vicompte, Blick vom Kanal zum Schloß. Stich von I. Silvestre. In: Marie Luise Gothein (1914), Geschichte des Gartenkunst, Jena: Diederichs, Bd. II, p. 138, Abb. 395. 


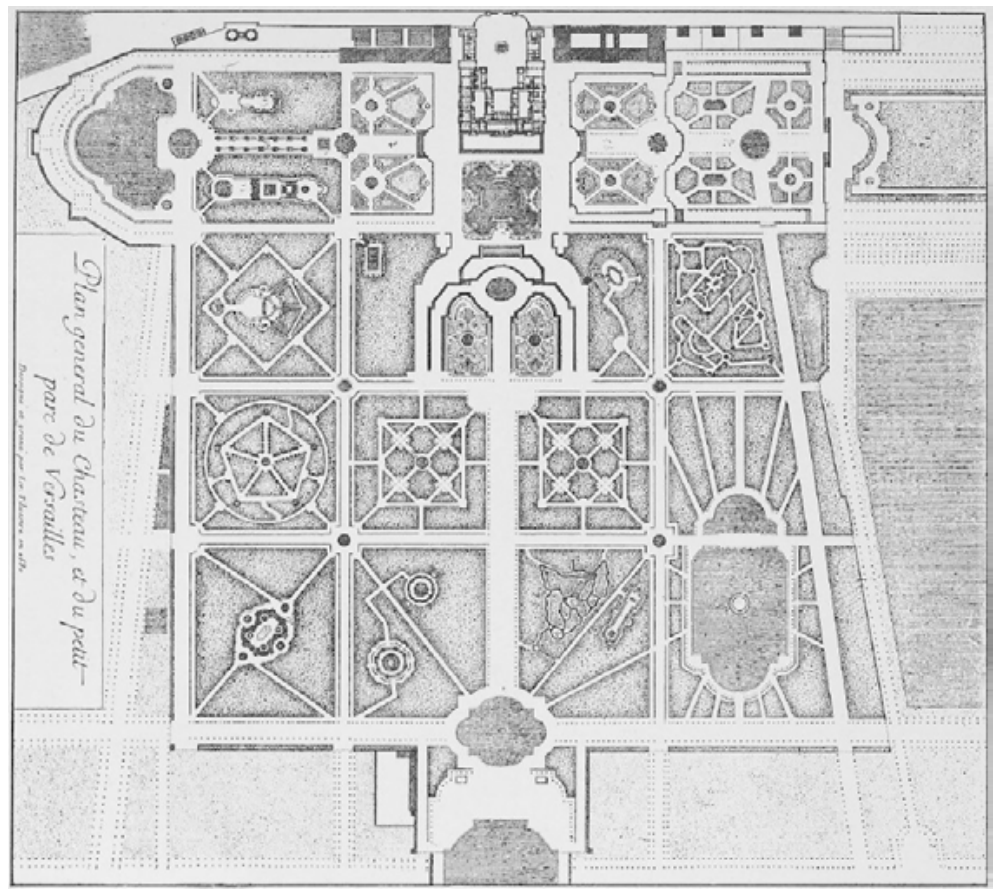

Abb. 14: Versailles, Plan des 'petit parc' 1680. Stich von I. Silvestre. In: Marie Luise Gothein (1914), Geschichte der Gartenkunst, Jena: Diederichs, Bd. II, p. 139, Abb. 396.

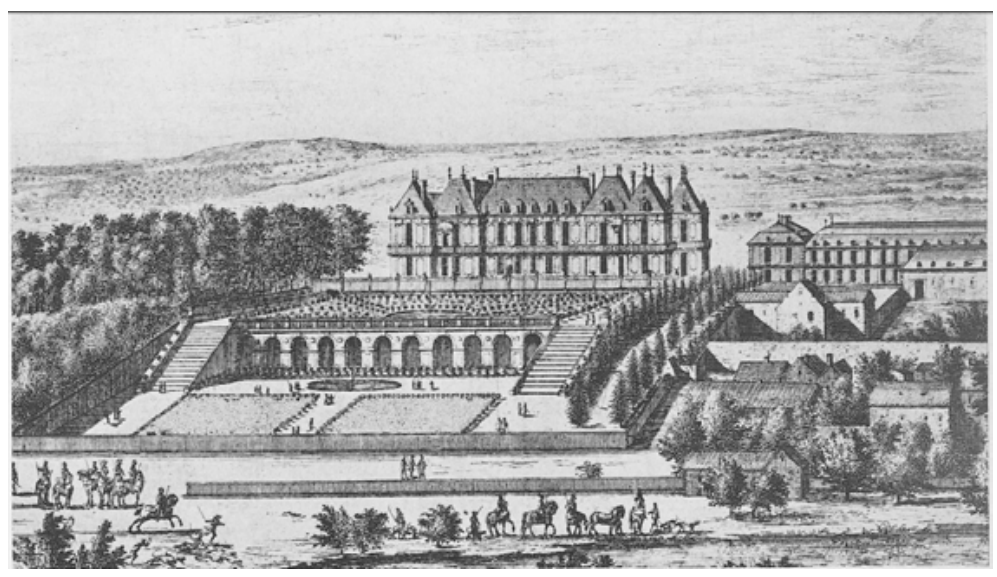

Abb. 15: Versailles, Schlüßchen Ludwigs XIII. mit der ersten Orangerie von Le Vau. Stich von I. Silvestre. In: Marie Luise Gothein (1914), Geschichte der Gartenkunst, Jena: Diederichs, Bd. II, p. 140, Abb. 397. 


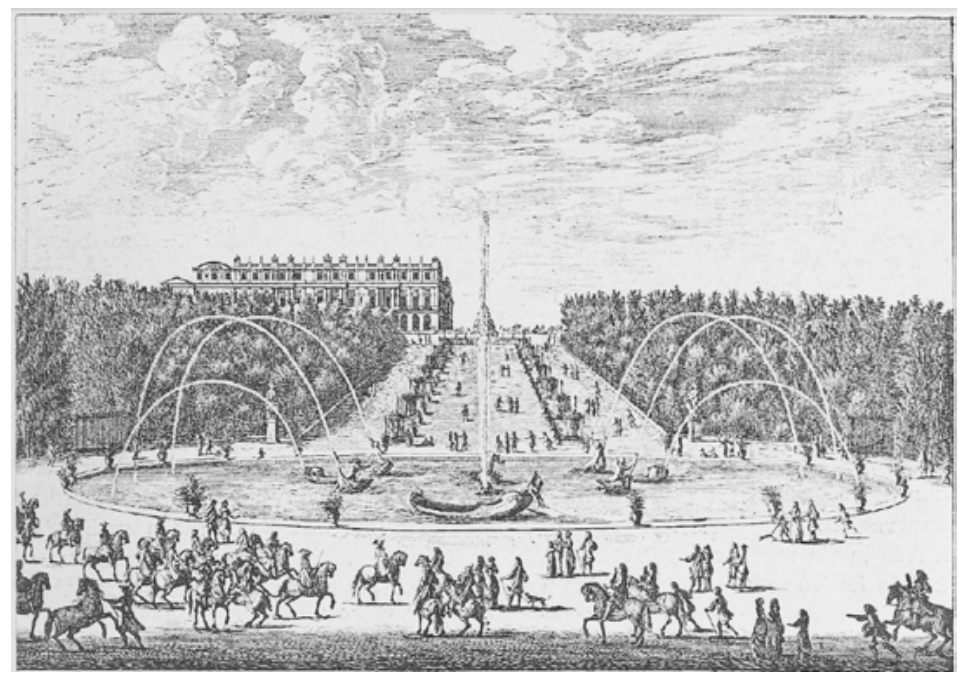

Abb. 16: Versailles, Wasserallee und Drachenbrunnen 1676 (späters Neptunbassin). Stich von I. Silvestre. In: Marie Luise Gothein (1914), Geschichte der Gartenkunst, Jena: Diederichs, Bd. II, p. 141, Abb. 398.

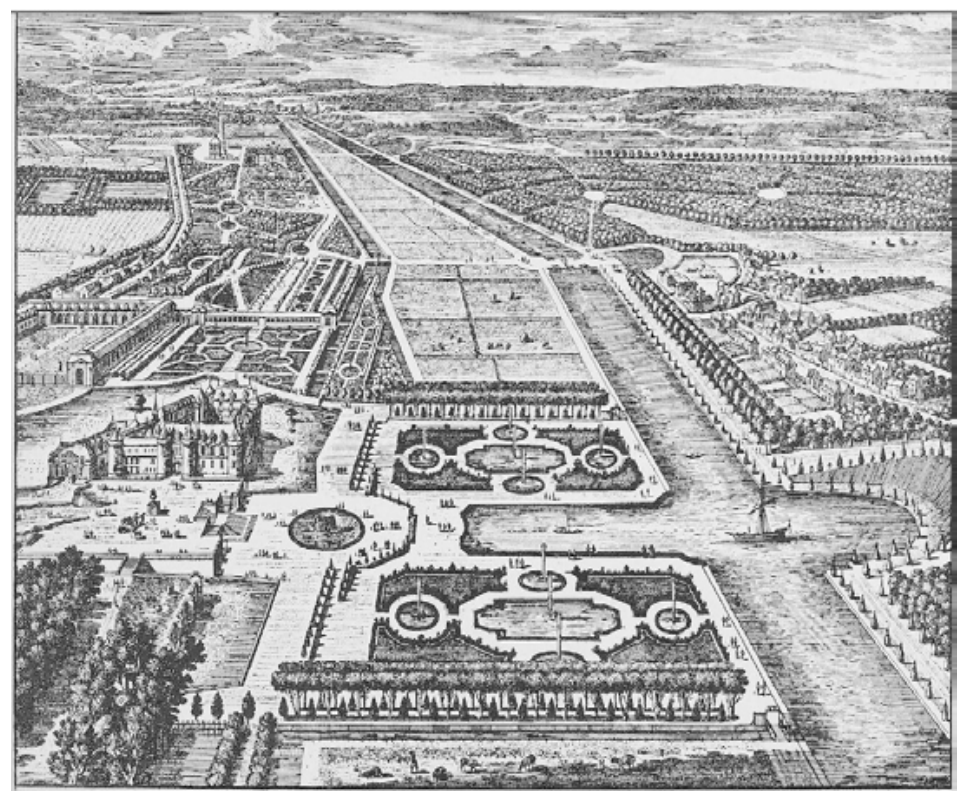

Abb. 17: Chantilly, Gesamtansicht. Nach N. Langloirs. In: Marie Luise Gothein (1914), Geschichte der Gartenkunst, Jena: Diederichs, Bd. II, p. 175, Abb. 426. 


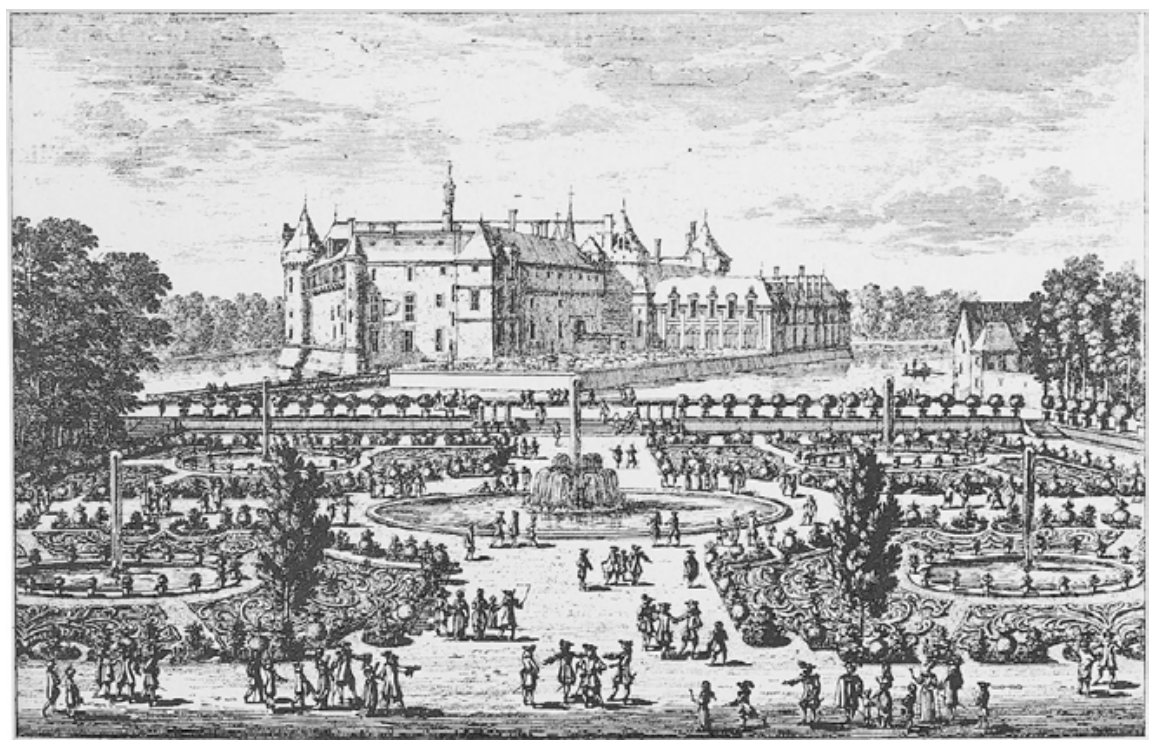

Abb. 18: Chantilly, Blumenparterre. Stich von Perelle. In: Marie Luise Gothein (1914), Geschichte der Gartenkunst, Jena: Diederichs, Bd. II, p. 177, Abb. 428.

\section{Literaturverzeichnis}

Dehio, Georg (1919): Geschichte der deutschen Kunst. Leipzig u. Berlin: De Gruyter. Gothein, Marie Luise (1914): Geschichte der Gartenkunst. Bd. 1-2. Jena: Diederichs. Haering, Theodor L. (1921): Die Struktur der Weltgeschichte. Tübingen: Mohr. Heussi, Karl (1932): Die Krisis des Historismus. Tübingen: Mohr.

Orsucci, Andrea (2012): Da Nietzsche a Heidegger. Mondo classico e civiltà europea. Pisa: Edizioni della Normale.

Riegl, Alois (1901): Die spätrömische Kunst-Industrie. Wien: Hof- und Staatsdrückerei.

Schroeter, Manfred (1922): Der Streit um Spengler. München: Beck.

Spengler, Oswald (1972): Der Untergang des Abendlandes. Umrisse einer Morphologie der Weltgeschichte (1923). München: Deutscher Taschenbuch Verlag.

Troeltsch, Ernst (1922): Das Historismus und seine Probleme (Gesammelte Schriften, Bd. 3). Tübingen: Mohr.

Worringer, Wilhelm (1912): Formprobleme der Gotik. München: Piper. 
